\title{
Potential masking effect on dyspnoea perception by short- and long-acting $\beta_{2}$-agonists in asthma
}

\author{
C.P. van Schayck*,\#, I.D. Bijl-Hofland*, S.G.M. Cloosterman*, H.T.M. Folgering", \\ F.J.J. van der Elshout ${ }^{+}$, C. Van Weel*
}

Potential masking effect on dyspnoea perception by short- and long-acting $\beta_{2}$-agonists in asthma. C.P. van Schayck, I.D. Bijl-Hofland, S.G.M. Cloosterman, H.T.M. Folgering, F.J.J. van der Elshout, C. Van Weel. C ERS Journals Ltd 2002.

ABSTRACT: Asthma patients evaluate the effect of medication treatment through the degree of their asthma symptoms, which might be affected by their ability to perceive these symptoms. It has been suggested that $\beta_{2}$-agonists may mask the effects of an increase in airway inflammation. This study compared the perception of histamineinduced bronchoconstriction during monotherapy with short- or long-acting $\beta_{2}$-agonists.

Asthmatic patients $(68$ male and 60 female, mean age $35 \pm 11$ yrs, forced expiratory volume in one second (FEV1) 86 $\pm 15 \%$ of the reference value, provocative concentration causing a $20 \%$ fall in FEV1 (PC20) geometric mean $0.97 \mathrm{mg} \cdot \mathrm{mL}^{-1}(95 \%$ confidence interval (CI): 0.73-1.30)) were selected and randomly allocated to use either a shortacting (salbutamol, $n=41$ ) or long-acting $\beta_{2}$-agonist (formoterol, $n=46$ ) or placebo $(\mathrm{n}=41)$ for 12 weeks. Perception of dyspnoea provoked by histamine-induced bronchoconstriction was measured at the start and every 4 weeks thereafter. Subjects quantified their sensation of breathlessness during the challenge tests on a modified Borg scale at the start of the study and every 4 weeks thereafter. The sensitivity to changes in FEV1 was analysed by the linear regression slope $(\alpha)$ Borg versus $\%$ fall in FEV1. The absolute perceptual magnitude (PS20) was determined by the perception score at the $20 \%$ fall in FEV1.

Although the geometric mean PC20 decreased significantly within the group using short-acting $\beta_{2}$-agonists (in the group with initial $P C_{20} \geqslant 2 \mathrm{mg} \cdot \mathrm{mL}^{-1}$ there was a drop from $5.26-1.94 \mathrm{mg} \cdot \mathrm{mL}^{-1} ; \mathrm{p}=\mathbf{0 . 0 1 3}$ ), repeated measurement analysis showed no difference in the course of time of perception (both slope $\alpha$ and PS20) between the three medication groups.

This study showed that chronic use of short- or long-acting $\beta_{2}$-agonists in asthmatics for a period of 12 weeks, did not significantly change the perception of histamineinduced bronchoconstriction compared with placebo. Further investigation is required to establish whether this suggests that these drugs do not mask a deterioration of asthma. Eur Respir J 2002; 19: 240-245.
* Dept of General Practice, University of Nijmegen, "Dept of General Practice, University of Maastricht, "Dept of Pulmonary Diseases, Dekkerswald, University of Nijmegen and ${ }^{+}$Dept of Pulmonary Diseases, Rijnstate Hospital, Arnhem, the Netherlands.

Correspondence: C.P. van Schayck Dept of General Practice

University of Maastricht

P.O. Box 616

6200 MD Maastricht

The Netherlands

Fax: 31433884225

E-mail: onno.vanschayck@hag.unimaas. $\mathrm{nl}$

Keywords: Asthma dyspnoea perception long-acting $\beta_{2}$-agonist short-acting $\beta_{2}$-agonist

Received: January 182001

Accepted after revision October 20 2001
It has been suggested that $\beta_{2}$-agonists may mask the effects of an increase in airway inflammation [1]. This may be particularly true for patients who use little or no anti-inflammatory treatment. There are several reasons why perception of asthma symptoms might be influenced by chronic bronchodilator use. First, chronic bronchodilator use leads to a decrease in bronchoconstriction, which might influence perception of the severity of the disease. The reduced perception of asthma symptoms could influence the patient's healthcare behaviour. For example, a patient might be more exposed to allergens because they have no inclination to stay away from them, as there is no warning against repeated exposure. Patients could also become noncompliant with anti-inflammatory treatment and, in the meantime, develop progressive inflammation with increasing bronchial hyperresponsiveness (BHR). Secondly, several studies have observed that chronic use of short-acting $\beta_{2}$-agonists may have detrimental effects, resulting in increased
BHR [1-5]. Chronic use of $\beta_{2}$-agonists has led to tolerance of their protective effects against bronchoconstrictor stimuli, whereas their bronchodilator properties have remained unchanged [4, 6, 7]. Furthermore, it has been found that BHR may have a negative influence on the perception of asthma symptoms [8, 9]. Previously, RoIsman et al. [10] showed that both the degree of eosinophil inflammation and epithelial damage presented in the airways are negatively related to the patient's ability to perceive bronchoconstriction. Finally, the patient's increased bronchial responsiveness may chronically adapt them to their increased bronchoconstriction [8].

It is therefore important to study the effects of bronchodilator use on the perception of airway obstruction. In this study, it was hypothesized that increased BHR after chronic use of $\beta_{2}$-agonists would lead to a decrease in the perception of airway obstruction. The perception of histamine-induced bronchoconstriction has been assessed by two indices 
representing different aspect of the perception: the sensitivity index and the absolute perceptual magnitude (PS20) [9-13].

Recently, the authors showed that in a small group of 64 asthmatic patients, additional use of inhaled corticosteroids resulted in an improved perception of bronchoconstriction in patients using long-acting $\beta_{2}$-agonists [14]. In the study, patients used either a short- or long-acting $\beta_{2}$-agonists or placebo over a period of 12 weeks, followed by another period of 12 weeks in which beclomethasone diproprionate was added. However, as the study group was a subgroup of the present population, it was too small to compare the effects of long- and short-acting $\beta_{2}$-agonists. The number of subjects in the present study population was sufficient to study differences between long- and short-acting $\beta_{2}$-agonists.

The perception of bronchoconstriction during chronic use of $\beta_{2}$-agonists was examined both for short-acting and long-acting $\beta_{2}$-agonists. This was performed through measurement of the perception of dyspnoea during histamine-induced bronchoconstriction in asthmatic patients who randomly received salbutamol (2 inhalations $100 \mu \mathrm{g}$ b.i.d.), formoterol $(12 \mu \mathrm{g}$ b.i.d. $)$ or placebo for 12 weeks.

\section{Methods}

\section{Patient selection}

Selection of the patients was performed through a two-step procedure. Initially, patients (aged 1660 yrs) were selected by their general practitioner (GP) if they had a history of bronchial symptoms or a clinical diagnosis of asthma [13, 14]. Eligible patients then visited the lung function laboratory for an inclusion assessment. Patients had to have lower airway complaints, a forced expiratory volume in one second (FEV1) of $\geqslant 50 \%$ of predicted and either airway hyperresponsiveness (provocative concentration causing a $20 \%$ fall in FEV1 (PC20) on histamine $\leqslant 8 \mathrm{mg} \cdot \mathrm{mL}^{-1}$ )) or reversibility of obstruction (of $\geqslant 15 \%$ compared to baseline FEV1 after inhalation of $800 \mathrm{mg}$ salbutamol) to be eligible for inclusion in the study. Bronchodilator response was assessed after histamine provocation when the FEV1 had returned to the baseline value. A total of 258 patients met these criteria, of whom 204 agreed to participate in the study. Informed consent was obtained from each patient and the ethical committee of the Academic Hospital of Nijmegen University, the Netherlands, approved the study.

\section{Study design}

At the start of the 8-week washout period, patients ceased all their pulmonary medication (inhaled corticosteroids, cromoglycates, bronchodilators), if used, and were instructed to use only rescue medication on demand (Berodual $(\mathrm{R})$ dry powder inhalation with ipratropium bromide $40 \mu \mathrm{g}$ and fenoterol hydrobromide $100 \mu \mathrm{g}$ ). After the washout period, each subject randomly received either a short-acting (salbutamol metered-dose inhaler with two inhalations $100 \mu \mathrm{g}$ b.i.d.) or a long-acting (formoterol metered-dose inhaler with $12 \mu \mathrm{g}$ b.i.d.) $\beta_{2}$-agonist or a placebo for 12 weeks. Patients came to the laboratory at the start of the treatment period and every 4 weeks thereafter. Patients received the study medication on the entry day and were carefully instructed on how to use the medication (inhaler technique and time schedule). Their use of the medication was then checked during every visit to the laboratory: used canisters were collected and weighed before and after use in order to check compliance.

A subgroup of 64 of these patients was followed up for a second period in which they received additional inhaled corticosteroids. That study has been recently reported elsewhere [14].

\section{Bronchial provocation}

During each visit to the laboratory, patients underwent a histamine challenge test according to European Respiratory Society (ERS) standards [15]. No study medication was used for $\geqslant 12 \mathrm{~h}$ before the test. Doubling doses of histamine, starting with 0.03 and going up to $16 \mathrm{mg} \cdot \mathrm{mL}^{-1}$, were administered until FEV1 had dropped by $\geqslant 20 \%$ compared to baseline value, or a maximum of $16 \mathrm{mg} \cdot \mathrm{mL}^{-1}$ histamine was given. The bronchial response to each dose of histamine was expressed as the reduction in FEV1 as a percentage of baseline value, according to ERS standards [15]. The dose of inhaled histamine, causing a $20 \%$ fall in FEV 1 below baseline, was obtained from the log dose-response curve by linear interpolation of the last two points. PC20 was recorded in noncumulative units.

\section{Assessment of breathlessness}

Breathlessness was measured during the histamine challenge, before each measurement of FEV1 with a modified Borg scale [16]. The Borg scale is a 12point ordinal scale ranging from 0 (no respiratory complaints) and 0.5 (very, very slight respiratory complaints) to 10 (maximal respiratory complaints). Subjects were instructed that the term "respiratory complaints" meant "complaints of respiratory sensation such as shortness of breath, chest tightness and breathlessness". Subjects were asked to score the overall magnitude of all three symptoms together in one assessment. Other histamine-related symptoms, such as pharyngitis or conjunctivitis, headaches or cough, were not scored. In order to determine the patient's "perceptiveness" during the study, they had to have a baseline FEV $1 \geqslant 50 \%$ pred at the start of the bronchial provocation test, and, during this test, the PC20 value had to be established with at least two doubling doses of histamine.

\section{Analysis}

Perception of bronchoconstriction during the histamine challenge test was analysed by calculating the 
linear regression coefficient (slope $\alpha$ ) between Borg scores and the reduction in FEV1 as a percentage of the baseline value in the linear regression analysis of Borg $=\mathrm{y}+\alpha \% \Delta \mathrm{FEV} 1$, indicating the patient's sensitivity towards changes in FEV1 [8, 10, 12, 13]. Furthermore, Borg scores corresponding to a reduction in FEV1 of $20 \%$ were determined by interpolation, reflecting the PS20 [9, 11, 13, 17]. All PC20 values were log-transformed before analysis. The effect of chronic bronchodilator use on BHR was determined with a paired t-test between baseline and the last follow-up measurement of PC20.

Repeated measurement analysis was used to analyse the changes in PC20 and Borg scores, based on the mixed model (PROC MIXED in SAS) and with special parametric structure on the covariance (correlation) matrices. Both within- and between-group factors can be analysed in this model. All analyses were corrected for baseline perception score, baseline bronchial responsiveness (PC20) and baseline FEV1 $\%$ pred by means of covariance analysis. All analyses were performed on the group of patients with either an initially high or low bronchial responsiveness $\left(\mathrm{PC}_{20}<2 \mathrm{mg} \cdot \mathrm{mL}^{-1}\right.$ versus $\left.\mathrm{PC} 20 \geqslant 2 \mathrm{mg} \cdot \mathrm{mL}^{-1}\right)$, in order to investigate the affect on $\mathrm{PC}_{20}$ in asthmatic patients in which there was "enough room for deterioration" (patients with a relatively high baseline PC20). A cut-off point of $2 \mathrm{mg} \cdot \mathrm{mL}^{-1}$ was chosen as this was the median of the PC20 baseline. Finally, the perceptual sensitivity (slope $\alpha$ ) and PS20 of patients with either an initially high or low bronchial responsiveness were compared by an unpaired t-test. This was performed at baseline and every 4 weeks thereafter (four measurements).

\section{Power calculation}

A clinically relevant difference in perception was assumed to be at least 1.0 step on the Borg scale. Assuming an SD of 1.5 steps (which was found in these allergic asthmatic patients), an $\alpha$ of 0.05 and a $\beta$ of $0.2, \geqslant 36$ evaluable patients were needed per group. With a drop-out rate of $15 \%$, the number of patients starting per group was $\geqslant 41$.

\section{Results}

\section{Patients}

Of the 204 patients who started the washout period, 42 subjects dropped out before the medication treatment period began, mainly because they could not stop using inhaled corticosteroids. During the medication period, five subjects dropped out because they needed inhaled corticosteroid treatment, five subjects refused to take the study medication, and six patients stopped due to motivational factors. Baseline perception measurement and/or the followup perception measurements could not be assessed in 18 subjects, because their FEV1 was $<50 \%$ pred at the time of assessment. Therefore, the total number of patients left for analysis was 128. The clinical characteristics of these asthmatic patients are presented in table 1. During the study, there was no difference in the number of patients using rescue medication (78\% in the short-acting, $83 \%$ in the longacting and $83 \%$ in the placebo group; $\mathrm{p}=0.82$ ).

\section{Bronchial hyperresponsiveness}

The course of BHR during 12 weeks of chronic bronchodilator use in the group with an initially high and low BHR $\left(\mathrm{PC}_{20}<2 \mathrm{mg} \cdot \mathrm{mL}^{-1}\right.$ versus $\mathrm{PC}_{20}$ $\geqslant 2 \mathrm{mg} \cdot \mathrm{mL}^{-1}$ ) is shown in figures 1 and 2 . In the group with an initially low bronchial responsiveness using chronic short-acting $\beta_{2}$-agonists, the PC20 decreased significantly from $5.26 \mathrm{mg} \cdot \mathrm{mL}^{-1} \quad(95 \%$ confidence interval (CI): $3.71-7.45)$ to $1.94 \mathrm{mg} \cdot \mathrm{mL}^{-1}(95 \% \mathrm{CI}$ : $0.84-4.48 ; \mathrm{p}=0$. 013).

Perceptive sensitivity for changes in forced expiratory volume in one second

There were no significant differences in the perceptive sensitivity of changes in FEV1 (slope $\alpha$ ) between

Table 1.-Baseline characteristics of the study population

\begin{tabular}{|c|c|c|c|c|}
\hline & Short-acting & Long-acting & Placebo & p-value \\
\hline Patients $n$ & 41 & 46 & 41 & \\
\hline Age yrs & $34.8 \pm 10.6$ & $33.7 \pm 11.5$ & $35.8 \pm 12.3$ & 0.687 \\
\hline Sex F/M & $17 / 24$ & $23 / 23$ & $20 / 21$ & 0.697 \\
\hline $\mathrm{PC} 20 \mathrm{mg} \cdot \mathrm{mL}^{-1 \#}$ & $1.03(0.60-1.78)$ & $0.89(0.54-1.47)$ & $1.00(0.64-1.58)$ & 0.911 \\
\hline FEV1 $\mathrm{ml}$ & $3362 \pm 719$ & $3195 \pm 611$ & $3056 \pm 787$ & 0.150 \\
\hline FFV $1 \%$ pred & $88 \pm 13$ & $86 \pm 14$ & $83 \pm 17$ & 0.315 \\
\hline $\begin{array}{l}\text { Patients on inhaled steroids before } \\
\text { the start of the trial } \%\end{array}$ & 44 & 54 & 56 & 0.486 \\
\hline \multicolumn{5}{|l|}{ Perception indices } \\
\hline Slope $>$ Borg $/ \%$ reduction in FEV 1 & $0.12 \pm 0.06$ & $0.11 \pm 0.08$ & $0.11 \pm 0.06$ & 0.834 \\
\hline $\begin{array}{l}\text { PS20 }>\text { Borg at } 20 \% \text { reduction in } \\
\text { FEV } 1\end{array}$ & $4.4 \pm 2.9$ & $3.6 \pm 1.8$ & $4.2 \pm 2.0$ & 0.222 \\
\hline
\end{tabular}

Data are presented as mean \pm SD unless otherwise stated. FEV1: forced expiratory volume in one second; PC20: provocative concentration causing a 20\% fall in FEV1; PS20: absolute perceptual magnitude; F: female; M: male. ${ }^{\#}$ : geometric mean ( $95 \%$ confidence interval). 


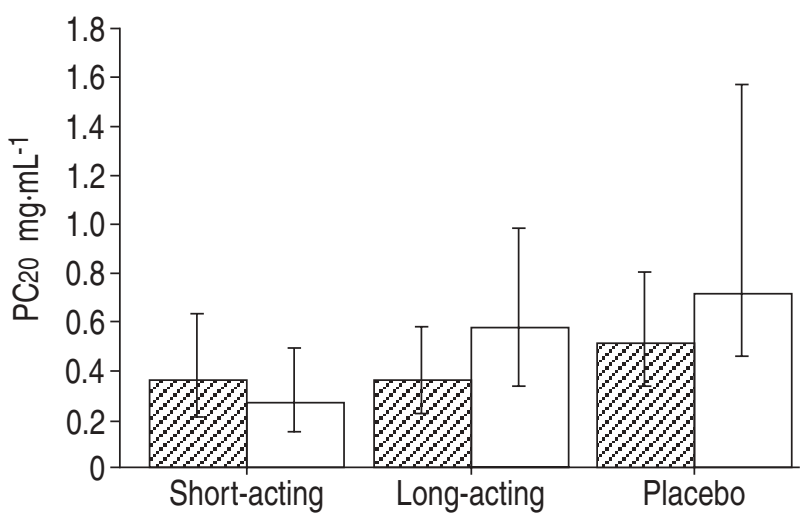

Fig. 1.-Effects of 12 weeks of chronic $\beta_{2}$-agonist use on the provocative concentration causing a $20 \%$ fall in forced expiratory volume in one second ( $\left.\mathrm{PC}_{20}\right)$ in patients with an initially high bronchial hyperresponsiveness $\left(\mathrm{PC} 20<2 \mathrm{mg} \cdot \mathrm{mL}^{-1}\right)$. $\mathbb{Z}$ : baseline; $\square$ : 12 weeks.

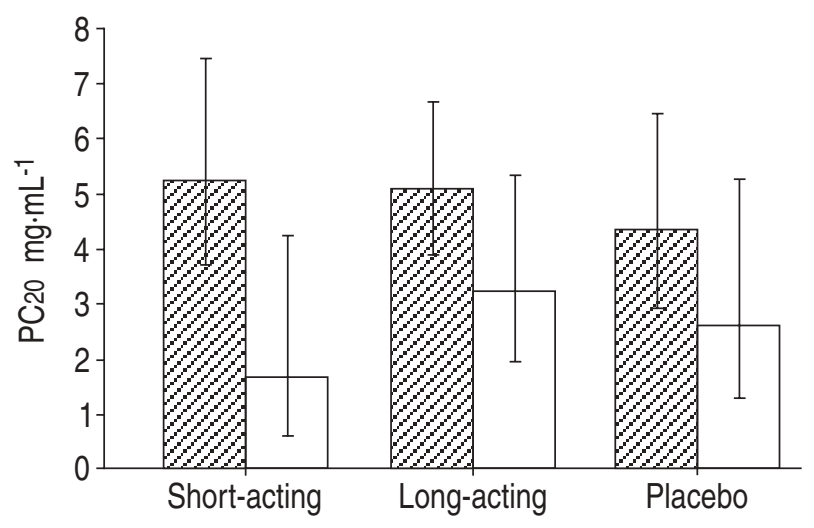

Fig. 2.-Effects of 12 weeks of chronic $\beta_{2}$-agonist use on the provocative concentration causing a $20 \%$ fall in forced expiratory volume in one second $\left(\mathrm{PC}_{20}\right)$ in patients with an initially low bronchial hyperresponsiveness $\left(\mathrm{PC}_{20} \geqslant 2 \mathrm{mg} \cdot \mathrm{mL}^{-1}\right)$. $\square$ : baseline; $\square$ : 12 weeks.

the three medication groups at the start of the study (table 1). Repeated measurement analysis showed no difference in the course of time of slope $\alpha$ between the three medication groups both for the total group and the group of patients with either an initially high or low bronchial responsiveness $(\mathrm{p}=0.98$ and $\mathrm{p}=0.42$, respectively, fig. 3).

\section{Absolute perceptual magnitude}

There were no significant differences in the perception score at 20\% reduction in FEV1 (PS20) between the three medication groups at the start of the study (table 1). Repeated measurement analysis also showed no difference in the course of time of PS20 between the three medication groups both for the total group and for the group of patients with either an initially high or low bronchial responsiveness $(\mathrm{p}=0.72$ and $\mathrm{p}=0.18$, respectively, fig. 4).

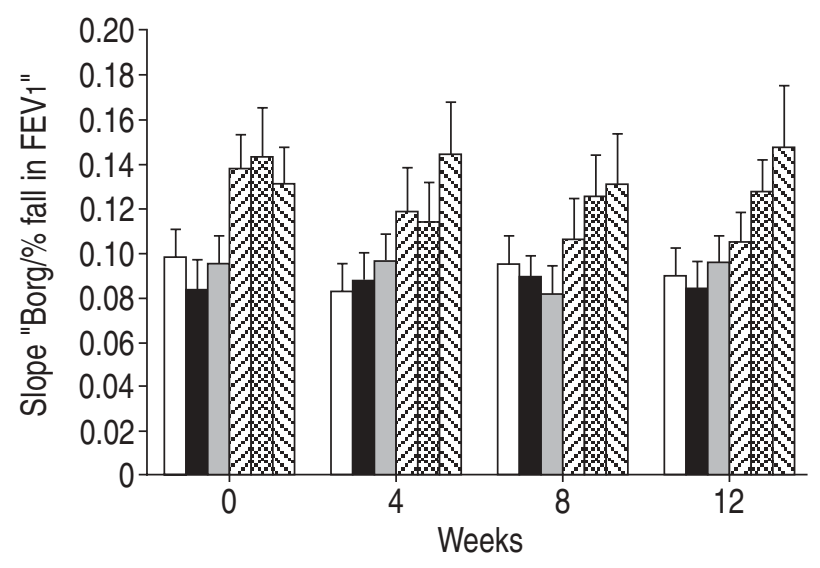

Fig. 3.-Perceptual sensitivity of histamine-induced bronchoconstriction (slope $\alpha$ ) during regular use of $\beta_{2}$-agonists in subjects with an initially high provocative concentration causing a $20 \%$ fall in forced expiratory volume in one second (FEV1) (PC20 $<2 \mathrm{mg} \cdot \mathrm{mL}^{-1} ; \square$ : short-acting; $\boldsymbol{\square}$ : long-acting; $\square$ : placebo) and low bronchial hyperresponsiveness $\left(\mathrm{PC}_{20} \geqslant 2 \mathrm{mg} \cdot \mathrm{mL}^{-1}\right.$; $\mathbb{Z}$ : shortacting; : long-acting; $\mathbb{\mathbb { Q }}$ : placebo).

\section{Discussion}

This study shows that chronic use of $\beta_{2}$-agonists does not significantly change perception of histamineinduced bronchoconstriction compared with placebo, either for short- or long-acting $\beta_{2}$-agonists during a period of 12 weeks of daily use. In addition, it confirms the results of Boulet et al. [9], who also studied the perception of induced bronchoconstriction in asthmatic patients and showed that use of longacting $\beta_{2}$-agonists (salmeterol $1 \times 50 \mu \mathrm{g}$ b.i.d. during 4 weeks) does not impair the perception of bronchospasm [11].

Chronic use of $\beta_{2}$-agonists might increase the risk of BHR, cause greater airway inflammation and eventually lead to a reduction in the perception of bronchoconstriction. The authors previously reported

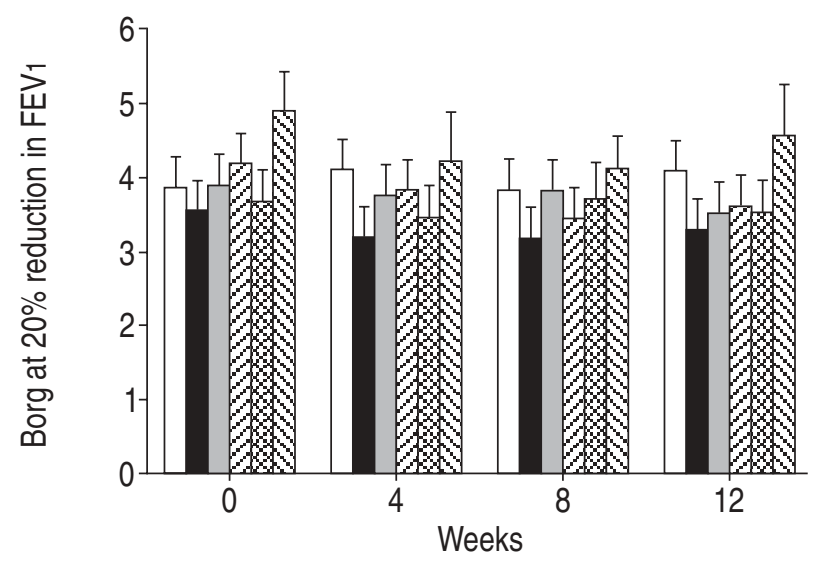

Fig. 4.-Absolute perceptual magnitude (PS20) of histamineinduced bronchoconstriction during regular use of $\beta_{2}$-agonists in subjects with an initially high provocative concentration causing a $20 \%$ fall in forced expiratory volume in one second (FEV1) (PC20 $<2 \mathrm{mg} \cdot \mathrm{mL}^{-1} ; \square$ : short-acting; $\mathbf{\square}$ : long-acting; $\square$ : placebo) and low bronchial hyperresponsiveness $\left(\mathrm{PC}_{20} \geqslant 2 \mathrm{mg} \cdot \mathrm{mL}^{-1} ; \mathbb{Z}\right.$ : short-acting; $\mathbf{D}$ : long-acting; $\mathbb{\mathbb { N }}$ : placebo). 
that chronic use of short-acting $\beta_{2}$-agonists in subgroups of patients resulted in increased BHR and a greater decline in lung function [18]. In the present study, BHR increased in the group with an initially low bronchial responsiveness using chronic shortacting $\beta_{2}$-agonists. However, the increase in bronchial responsiveness did not lead to a decrease in the perception of bronchoconstriction.

It could be suggested that a study period of 12 weeks is too short to demonstrate the influence of increased hyperresponsiveness on the perception of bronchoconstriction. This is because the perception of bronchoconstriction may only be influenced after a prolonged reduction in BHR.

It was not possible to measure eosinophilic airway inflammation and epithelial damage in this study. Therefore, the study did not assess whether chronic $\beta_{2}$ agonist use led to increased inflammation in the airways of asthmatic subjects. It is important to emphasize that the perception of bronchoconstriction was measured, whereas the perception of a deteriorating asthma was not. This is important as $\beta_{2}$-agonists may prevent bronchoconstriction despite an increase in airway inflammation, underlying a deterioration of asthma.

An increase in BHR was only observed in the group using short-acting $\beta_{2}$-agonists but not when compared with the placebo group, as the difference in changes between these two groups was not significant. Recently, in a subgroup of the present study population [14], the authors showed that the additional use of inhaled corticosteroids resulted in an improvement in the perception of bronchoconstriction in patients using long-acting $\beta_{2}$-agonists but not in patients using short-acting $\beta_{2}$-agonists. This difference might be related to the increase in BHR in the group using short-acting $\beta_{2}$-agonists, resulting in greater airflow inflammation and perhaps a reduction in perception. Another possibility may be the suggested enhancement of the anti-inflammatory effects of corticosteroids by long-acting $\beta_{2}$-agonists [19].

The relevance of studying the effects of $\beta_{2}$-agonist monotherapy in asthma may be questioned, as it is advised that long-acting $\beta_{2}$-agonists are used in combination with inhaled steroids, whilst short-acting $\beta_{2}$-agonists should only be used without inhaled steroids in very mild intermittent asthma. However, there is still some concern that $\beta_{2}$-agonists might mask the effects of asthma, particularly because long-acting $\beta_{2}$-agonists suppress bronchoconstriction and may therefore eventually reduce compliance toward inhaled steroids. The present authors therefore believe that it is still clinically relevant to study the potential masking effects of these monotherapy drugs.

In summary, this study has shown that although chronic use of short-acting $\beta_{2}$-agonists led to increased bronchial hyperresponsiveness, it did not significantly change perception of histamine-induced bronchoconstriction compared with placebo, either for short- or long-acting $\beta_{2}$-agonists after a period of 12 weeks of daily use.

Acknowledgements. The authors gratefully acknowledge the cooperation of M. Habes,
I. van den Heuvel, E. Snakenborg and M. Thies in measuring the lung function, bronchial hyperresponsiveness, and breathlessness of the patients.

\section{References}

1. McIvor RA, Pizzichini E, Turner MO, Hussach P, Hargreave FE, Sears MR. Potential masking effects of salmeterol on airway inflammation in asthma. Am J Respir Crit Care Med 1998; 158: 924-930.

2. Sears MR, Taylor DR, Print CG, et al. Regular inhaled beta-agonist treatment in bronchial asthma. Lancet 1990; 336: 1391-1396.

3. van Schayck CP, Dompeling E, van Herwaarden CLA, et al. Bronchodilator treatment in moderate asthma or chronic bronchitis: continuous or on demand? A randomised controlled study. BMJ 1991; 303: A426-A431.

4. van Schayck CP, Graafsma SJ, Visch MB, Dompeling $E$, van Weel C, van Herwaarden CLA. Increased bronchial hyperresponsiveness after inhaling salbutamol during 1 year is not caused by subsensitization to salbutamol. J Allergy Clin Immunol 1990; 86: 793-800.

5. Cockcroft DW, McParland CP, Britto SA, Swystun VA, Rutherford BC. Regular inhaled salbutamol and airway responsiveness to allergen. Lancet 1993; 342: 833-837.

6. Arvidsson P, Larsson S, Löfdahl C-G, Melander B, Svedmyr N, Wåhlander L. Inhaled formoterol during one year in asthma: a comparison with salbutamol. Eur Respir J 1991; 4: 1168-1173.

7. Cheung D, Timmers MC, Zwinderman AH, Bel EH, Dijkman JH, Sterk PJ. Long-term effects of a longacting $\beta_{2}$-adrenoceptor agonist, salmeterol, on airway hyperresponsiveness in patients with mild asthma. N Engl J Med 1992; 327: 1198-1203.

8. Burdon JGW, Juniper EF, Killian KJ, Hargreave FE, Campbell EJM. The perception of breathlessness in asthma. Am Rev Respir Dis 1982; 126: 825-828.

9. Boulet LP, Cournoyer I, Deschesnes F, Leblanc P, Nouwen A. Perception of airflow obstruction and associated breathlessness in normal and asthmatic subjects: correlation with anxiety and bronchodilator needs. Thorax 1994; A9: 965-970.

10. Roisman GL, Peiffer C, Lacronique JG, Le Cae A, Dusser DJ. Perception of bronchial obstruction in asthmatic patients. Relationship with bronchial eosinophilic inflammation and epithelial damage and effect of corticosteroid treatment. J Clin Invest 1995; 96: 12-21.

11. Boulet L, Turcotte H, Cartier A, et al. Influence of beclomethasone and salmeterol on the perception of methacholine-induced bronchoconstriction. Chest 1998; 314: 373-379.

12. Marks GB, Yates DH, Sist M, et al. Respiratory sensation during bronchial challenge testing with methacholine, sodium metabisulphite, and adenosine monophosphate. Thorax 1996; 51: 793-798.

13. Bijl-Hofland ID, Cloosterman SGM, Folgering HThM, Akkermans RP, van den Hoogen $\mathrm{H}$, van Schayck CP. Measuring breathlessness during histamine challenge: a simple standardized procedure in asthmatic patients. Eur Respir J 1999; 13: 955-960.

14. Bijl-Hofland ID, Cloosterman SG, Folgering HT, 
van Den Elshout FJ, van Weel C, van Schayck CP. Inhaled corticosteroids, combined with long-acting $\beta_{2}$-agonists, improve the perception of bronchoconstriction in asthma. Am J Respir Crit Care Med 2001; 164: 764-769.

15. Sterk PJ, Fabbri LM, Quanjer PH, et al. Airway responsiveness: standardized challenge testing with pharmacological, physical and sensitizing stimuli in adults. Eur Respir J 1993; 6: 53-83.

16. Borg GAV. Psychophysical bases of perceived exertion. Med Sci Sports Exerc 1982; A4: 377-381.

17. Turcotte H, Corbeil F, Boulet LP. Perception of breathlessness during bronchoconstriction induced by antigen, exercise, and histamine challenges. Thorax 1990; 45: 914-918.

18. van Schayck CP, Cloosterman SG, Hofland ID, van Herwaarden CLA, van Weel C. How detrimental is chronic use of bronchodilators in asthma and chronic obstructive pulmonary disease? Am J Respir Crit Care Med 1995; 1151: 1317-1319.

19. Knox AJ, Zhu YM, Pang L. Do long-acting $\beta_{2^{-}}$ adrenoceptor agonists enhance the anti-inflammatory effect of glucocorticoids in asthma? Eur Respir J 2001; 117: 1059-1061. 